\title{
NATURAL AND ARTIFICIAL INTELLIGENCE IN CONSCIOUSNESS SOCIETY
}

\author{
${ }^{1}$ Todoroi Dumitru, ${ }^{2}$ Mihalcea Radu, ${ }^{3}$ Todoroi Nicoleta, ${ }^{3}$ Belinski \\ Dumitru, 4Nechita Elena, ${ }^{5}$ Belinski Tinca, ${ }^{6}$ Micuşa Dumitru
}

\author{
${ }^{1}$ ASEM, Republic of Moldova; ${ }^{2}$ Illinois University, Chicago, USA; ${ }^{3}$ Academia de \\ Muzică "Gh.Dima", Cluj-Napoca; "V. Alecsandri”" University at Bacău, \\ Romania; ${ }^{5}$ LYNN University, Florida, USA; ${ }^{6}$ ULIM, Republic of Moldova
}

\begin{abstract}
Consciousness Society is characterized by equality of structured Natural Intelligence (NIstructured) and Artificial (AI) ROBO-Intelligence. The purpose of research constitutes adaptable algorithmic process of robotic implementation of Artificial, Robotic Intelligences (AI) elements; there are used Adaptable Tools as Technological information methodology basis. There are analyzed creative, emotional, temperamental, and sensual sets of items which are to be implemented in ROBO-intelligences. They represent one axe of robotic tables constituting first level of ROBO-intelligences elements. Another dimension of these tables represents items' evolution functions. Functions are located on other axe of robotic matrices. This second axe represents intellectual, emotional, sensual, and spiritual evolution steps. Using adaptable tools of algorithmic definitions of robotic elements are defined superior, next level elements of ROBO - intelligences. Presented adaptable information technology for ROBO-intelligence's creation process is used in the institutional project "Creating Consciousness Society" that is developed in the period $2008-2018$ by the team of AESM and supporters.
\end{abstract}

Keywords: consciousness, natural, artificial, intelligence, robot, creativity, adaptability, society

\section{Introduction}

Taking "A machine can act intelligently" as a working hypothesis, many researchers have attempted to build such a machine. The purpose of the research is to find out the common moral principles for Artificial and Natural Intelligence that would serve a basis for successful interacting of robots with humans in future Consciousness Society.

Creative ROBO-intelligences will possess features which characterize highly creative people (natural intelligence). Character's creativity and emotion intelligences which are to be implemented in Character ROBOintelligences and Emotional ROBOintelligences are analysed and developed.

(1) The last time in European Community. Publications [1-3] confirm the European Community international interest [4] for AESM research results in the Branch of Conscience Society Creation process and in its engine for the process of creation ROBOintelligences, represented by the Adaptable Tools.

(2) Robots in Homo - Robotic Conscience Society. Committee on the problems of the European Parliament endorsed the draft recommendations, as well as the administrative regulations on the civilengineering production of robots. For that document voted PRO: 17 deputies, Against: 2 deputies, and Obtained: 2 deputies.

(3) Robot's Econometrics. According to data of the European Parliament, in the period 2010-2014 the average sales of robots was $17 \%$ annual and in 2015 has risen to 29 percent. Growth of robots developed the volume of patents in relation to robots - in the last 10 years the volume has doubled. Artificial intelligence will determine economic efficiency in such spheres as manufacturing, commerce, transport, medical service, education, case-law and agriculture. 
(4) Robot - legal status. It is not yet determined the legal status of robots, which soon will overwhelm us. Scientists are, as some carriers of artificial intelligence, provided with self-education capacity, separately, will need to be identified as "electronic faces" with corresponding Passport.

The document will contain the framework conditions for producers and users of robots, formulated since the great writer Isaac Azimov: 3 principles - the basic conditions in humans. collaboration with robots.

(5) Isaac Azimov: 3 principles. Asimov's Three Laws of Robotics, as they are called, have survived to the present:

1. Robots must never harm human beings or, through inaction, allow a human being to come to harm.

2.Robots must follow instructions from humans without violating rule 1 .

3.Robots must protect themselves without violating the other rules.

\section{Creative Approaches \& equation IQ = NIstructured}

Creative ROBO-intelligences (Creative IQ) will possess features which characterize highly creative people, Natural Intelligence (NIstructured) .

Currently popular creative approaches include

- Statistical methods,

- Computational intelligence and

- Adaptable symbolic IQ.

There are an enormous number of tools used in AI, including versions of:

- search and

- mathematical optimization,

- adaptable systems,

- logic,

- methods based on probability,

- economics,

- and many others.

\section{Problem's Solution Steps}

It is known: To solve the problem, computer specialist classically must:

1) formulates the problem,

2) formalizes the problem,

3 ) creates the algorithm of its solution,

4) codes the algorithm with the help of one of the programming languages,

5) debugs the program,

6) gathers documentation and

7) uses and maintain the obtained program product

2.1. Our goal is to use Adaptable Tools $[5,11]$ to develop first 3 steps of the ROBOintelligences creation.

2.2. Intelligence evolution: Piirto's $7 \mathrm{i}$ features which characterize highly creative people in ascending adaptable process of Piirto's Six Steps to the Creativity top develops next $\left(2^{\text {nd }}\right)$ level of IQ elements.

\subsection{Creative ROBO-intelligences [6]}

Creative ROBO-intelligences in

Conscience Society (Creative IQ) will possess the first level intelligent features (Piirto's 7i):

1. inspiration,

2. imagery (imaginerie),

3. imagination,

4. intuition,

5. insights (înseninare, озарение),

6. improvisation, and

7. incubation

which characterize highly creative people

Creative IQ will be touched by the hierarchical process of (1st level) 6 steps to the Creativity top:

1. acquiring knowledge,

2. developing curiosity,

3 . becoming interested,

4. passion,

5. dedication, and

6. professionalism

\section{ROBO-Intelligence based on Adaptable Processing}

Adaptabily Tools [5] represent our solution for Robotic problem. The adapter, as a meta-system tool, supports adaptable software and hardware flexibility: extension and reduction of ROBO-intelligences possibilities. By the help of adapter, it can be presented pragmatics, syntax, semantics, environ-ment, and examples of new or modified (next, $\mathbf{2}^{\text {nd }}$, level) elements of ROBO-intelligences.

4.1. The $2^{\text {nd }}$ Level IQ's elements: Adapter's general scheme: 
$\mathrm{BL}_{-}<$Pragmatics of ROBOintelligence element $>$ element>

$\mathrm{SY}_{-}<$Syntax of ROBO-intelligence

(1) _ $\mathrm{SE} \_<$Semantics of ROBOintelligence element $>$ element>

$\mathrm{CO}_{-}<$Context of ROBO-intelligence element $>$

EX_ $<$ Examples of ROBO-intelligence

EL_ and example (2) of it's implementation
4.2. The $2^{\text {nd }}$ Level IQ's elements: Example: Using adapter it is defined one of the new $\left(2^{\text {nd }}\right.$ level $)$ ROBO's element "Inspired passion":

_BL_ $<$ Inspired passion's pragmatics $>$

${ }_{-} \mathrm{SY}_{-}<$Inspired passion's syntax $>$

_SE _ < Inspired passion's semantics $>$

CO_< Inspired passion's usage context $>$

${ }_{-} \mathrm{EX}_{-}<$Inspired passion's examples call $>$ EL

Table 1. The $2^{\text {nd }}$ Level IQ's elements

\begin{tabular}{|c|c|c|c|c|c|c|}
\hline $\begin{array}{l}\text { Creativity } \\
\text { top } \\
\text { Versus } \\
\text { Creative } \\
\text { feature }\end{array}$ & $\begin{array}{l}\text { Acquire } \\
\text { Knowledge }\end{array}$ & $\begin{array}{l}\text { Develop } \\
\text { Curiosity }\end{array}$ & $\begin{array}{l}\text { Become } \\
\text { Interested }\end{array}$ & Passion & $\begin{array}{l}\text { Dedicatio } \\
\text { n }\end{array}$ & $\begin{array}{l}\text { Professi } \\
\text { onal- } \\
\text { ism }\end{array}$ \\
\hline Inspiration & $\begin{array}{l}\text { Inspiration } \\
\text { in } \\
\text { acquiring } \\
\text { Knowledge }\end{array}$ & & & $\begin{array}{l}\text { Inspired } \\
\text { passion }\end{array}$ & & \\
\hline Imagery & & $\begin{array}{l}\text { Imagery } \\
\text { developing } \\
\text { Curiosity }\end{array}$ & & & & \\
\hline $\begin{array}{l}\text { Imaginatio } \\
\text { n }\end{array}$ & & & $\begin{array}{l}\text { Imagina- } \\
\text { tion } \\
\text { becoming } \\
\text { interested }\end{array}$ & & & \\
\hline Intuition & & & & $\begin{array}{l}\text { Intuition' } \\
\text { s passion }\end{array}$ & & \\
\hline Insights & & & & & $\begin{array}{l}\text { Insights } \\
\text { dedication }\end{array}$ & \\
\hline $\begin{array}{l}\text { Improvi- } \\
\text { sation }\end{array}$ & & & & & & $\begin{array}{l}\text { Improvi } \\
\text { sation in } \\
\text { professi } \\
\text { onalism }\end{array}$ \\
\hline Incubation & & $\begin{array}{c}\text { Incubation } \\
\text { developing } \\
\text { Curiosity }\end{array}$ & & & & \\
\hline
\end{tabular}


4.3. The $2^{\text {nd }}$ Level IQ's elements: Commentaries:

(1) Pragmatics: name "Inspired passion";

(2) Syntax: "Inspiration in passion";

(3) Semantics: Correlation of functionalities of the $1{ }^{\text {st }}$ level of IQ elements: "Inspiration" and "Passion";

(4) Usage context: Evaluation from "Inspired passion" situation "Inspiratio become interested" to the next (top) situation "Inspired professionalism";

(5) Examples of "Inspired passion" (See: Next Table): "ROBO-intelligence became passionate by it business, it begin think to social profit."

4.4. The $2^{\text {nd }}$ Level IQ's elements (Table 1): Theorem "Creative ROBOintelligence"

If there are done: the 1st level of Creative
ROBO-intelligence's Piirto's 7i features which characterize highly creative people, the 1st level of Creative ROBO-intelligence's Piirto's six steps of the creativity top, and Adaptable tools it is possible to create all 2nd level elements of Creative ROBO-intelligence based on these IQ's 1st level elements.

\section{Emotional Intelligences}

Emotional ROBO-intelligence (EQ) refers to artificial (robotic) intelligence's ability to monitor their own and other intelligence's emotional states and to use this information to act wisely in relationships.

5.1. The $1^{\text {st }}$ level of $E Q$ elements: basic emotions.

Many psychologists believe that there are six main types of emotions, also called basic emotions. They are: 1. Happiness, 2. Sadness, 3. Fear, 4. Anger, 5. Disgust and 6. Surprise

Table 2. Adaptable evaluation steps

\begin{tabular}{|c|c|c|c|c|c|}
\hline $\begin{array}{l}\text { Evolution } \\
\text { of } \\
\text { Emotions }\end{array}$ & $\begin{array}{l}\text { Self- } \\
\text { awareness }\end{array}$ & $\begin{array}{l}\text { Managing } \\
\text { emotions }\end{array}$ & Motivation & Empathy & $\begin{array}{l}\text { Handling } \\
\text { relationships }\end{array}$ \\
\hline Happiness & $\begin{array}{l}\text { Happiness } \\
\text { self- } \\
\text { awareness }\end{array}$ & & & & \\
\hline Fear & & & & & $\begin{array}{l}\text { Fear handling } \\
\text { relationships }\end{array}$ \\
\hline Surprise & & $\begin{array}{l}\text { Surprise } \\
\text { managing }\end{array}$ & & & \\
\hline Disgust & & & $\begin{array}{l}\text { Disgust } \\
\text { motivation }\end{array}$ & & \\
\hline Sadness & & & & & \\
\hline Anger & & & & $\begin{array}{l}\text { Anger } \\
\text { empathy }\end{array}$ & \\
\hline
\end{tabular}


5.2.Adaptable evaluation steps (Table 2): the $2^{\text {nd }}$ level EQ elements

Emotional intelligence's adaptable evaluation steps are represented by:

1) Self-awareness: recognizing internal feelings;

2) Managing emotions: finding ways to handle emotions that are appropriate to the situation;

3) Motivation: using self-control to channel emotions toward a goal;

4) Empathy: understanding the emotional perspective of other people;

5) Handling relationships: using personal information and information about others to handle social relationships and to develop interpersonal skills

\section{ROBO-Temperaments}

\subsection{ROBO-Temperaments $1^{\text {st }}$ level EQ} elements

There exist four temperaments that a relatively simple but powerful way of classifying personalities: Melancholic,
Phlegmatic, Choleric, and Sanguine

\subsection{Theorem "Sanguine ROBO- intelligence"}

If there are done:

- the main features, characteristics, and functions of Sanguine type of temperaments (Figure 1),

- the Piirto's 7i features which characterize highly creative people, and

- Adaptable Tools

it is possible to create Sanguine ROBOintelligence with such features of creative artificial intelligence.

6.3. The $2^{\text {nd }}$ level of Character ROBOintelligences with seven features which characterize highly creative intelligence.

In the Table 3 there are present some $2^{\text {nd }}$ level elements o IQ which are presented by adaptable algorithms created on the base of temperament characteristics in composition with the seven features which characterize highly creative intelligence.

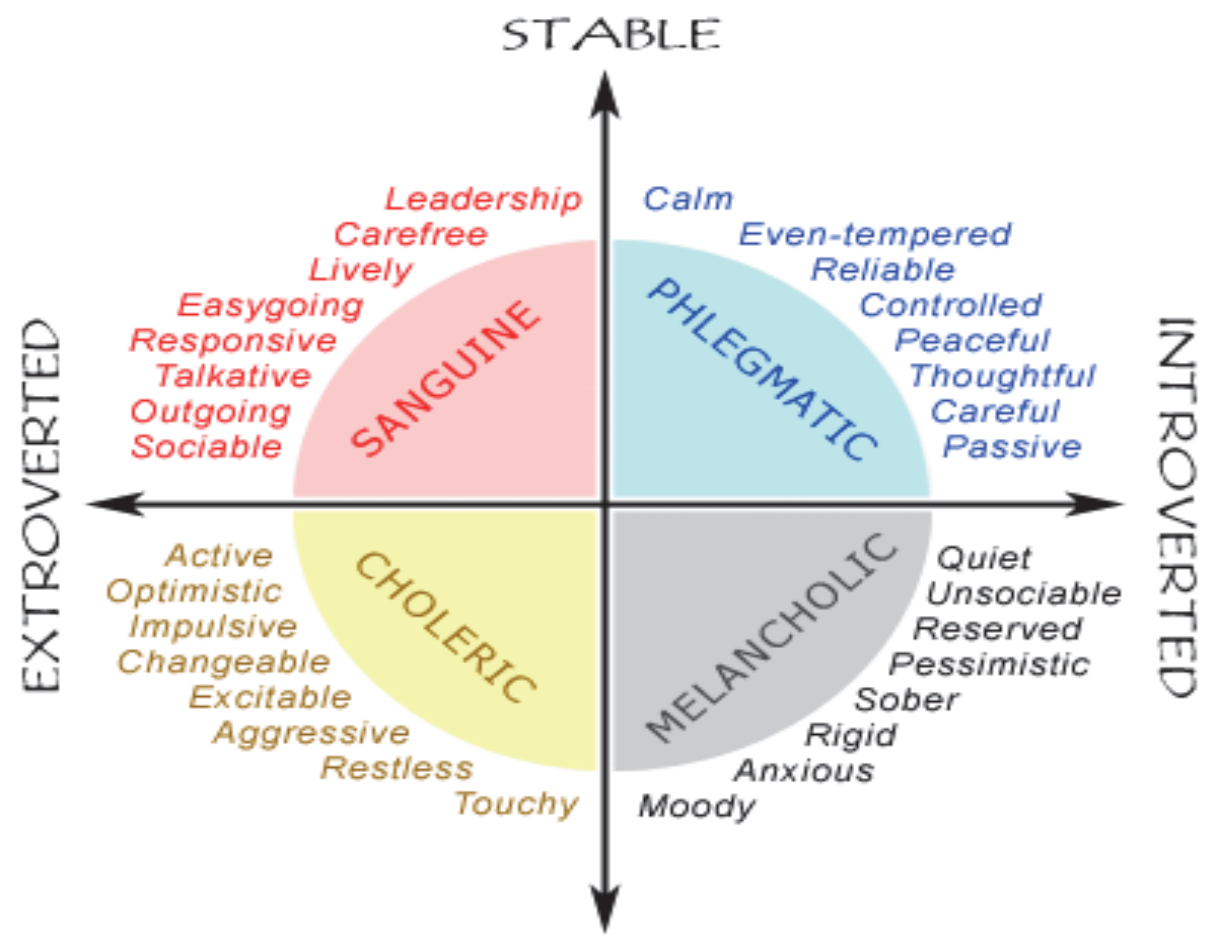

\section{UNST ABLE}

Figure 1. Temperaments 
Table 3. Temperament \& Creativity

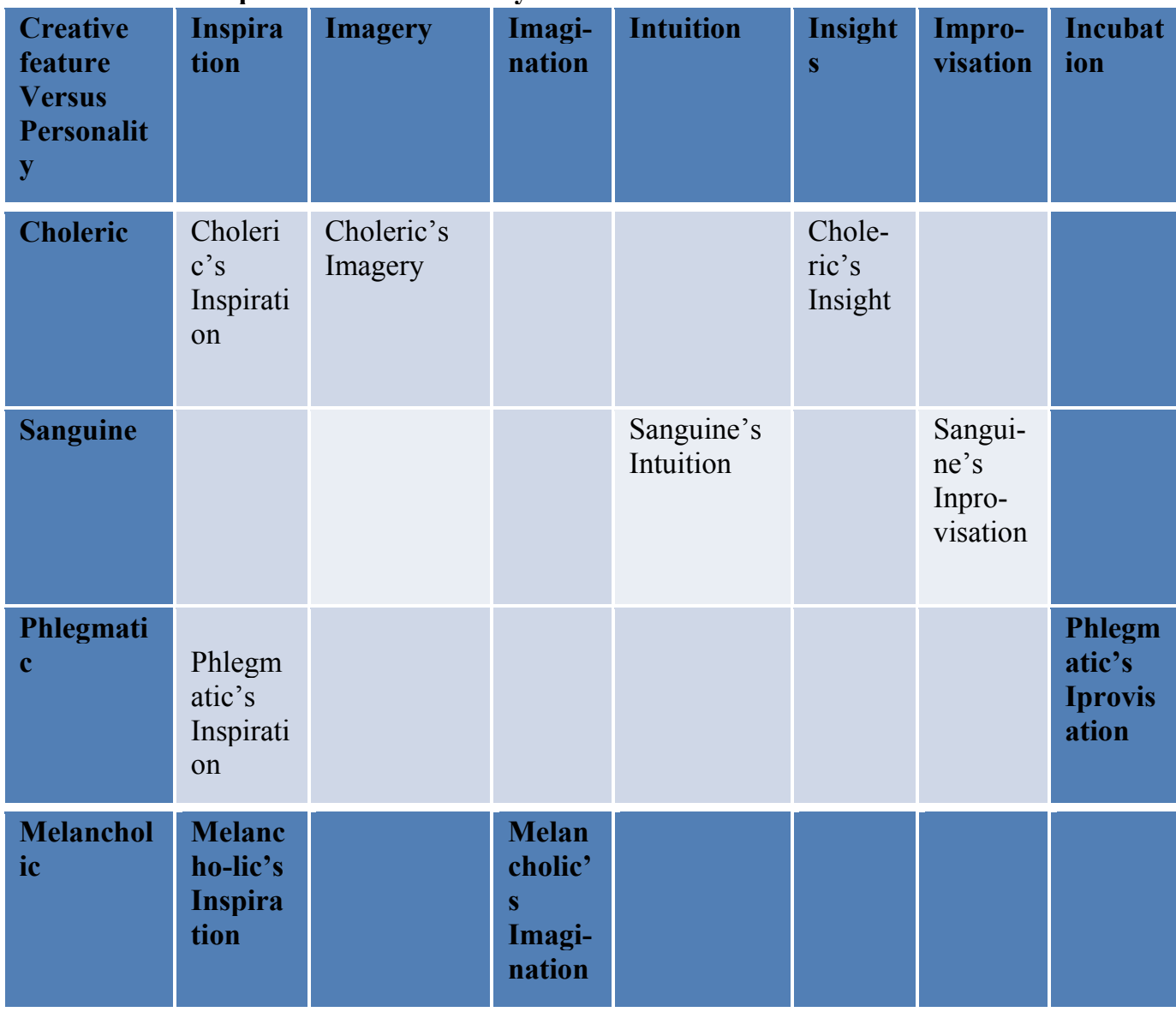

6.4. The $2^{\text {nd }}$ level of Character ROBO-intelligences evolution with Piirto's Six Steps to the Creativity top

In the Table 4 there are present some $2^{\text {nd }}$ level elements o IQ which are presented by adaptable algorithms created on the base of temperament characteristics in compo-sition with the Six Steps to the Creativity top.

6.5. Theorem "Choleric ROBOintelligence"

If there are done

(1) the main features, characteristics, and functions of Choleric type of temperaments,

(2) the first level Six Steps to the Creativity top elements of Character ROBO-intelligence (Table 4), and

(3) Adaptable Tools

it is possible to create Choleric ROBOintelligence.
6.6. Theorem "Emotional Phlegmatic ROBO-intelligence"

If there are done:

(1) the main features, characteristics, and functions of Phlegmatic type of temperaments,

(2) the first level Six Types of emotions elements of Character ROBO-intelligence, and

(3) Adaptable Tools

it is possible to create Emotional Phlegmatic ROBO-intelligence.

\subsection{Hierarchy of theorems}

Demonstration of Theorem "Choleric ROBO-intelligence" is based on such Lemmas as "Choleric acquires Knowledge", "Choleric develop Curiosity" and so on, which demonstrate the process of adaptable creation of 2nd level elements of Character ROBO-intelligences. 
Table 4. Temperament \& Creativity evolution

\begin{tabular}{|c|c|c|c|c|c|c|}
\hline $\begin{array}{l}\text { Creativity } \\
\text { top } \\
\text { versus } \\
\text { Peronalities }\end{array}$ & $\begin{array}{l}\text { Acquire } \\
\text { Knowledge }\end{array}$ & $\begin{array}{l}\text { Develop } \\
\text { Curiosity }\end{array}$ & $\begin{array}{l}\text { Become } \\
\text { Interes- } \\
\text { ted }\end{array}$ & Passion & Dedication & $\begin{array}{l}\text { Profes- } \\
\text { sionalism }\end{array}$ \\
\hline Choleric & & $\begin{array}{l}\text { Choleric } \\
\text { develop } \\
\text { Curiosity }\end{array}$ & & & & \\
\hline Sanguine & $\begin{array}{l}\text { Sanguine } \\
\text { acquires } \\
\text { Knowledge }\end{array}$ & & & & $\begin{array}{l}\text { Sanguine's } \\
\text { dedication }\end{array}$ & \\
\hline Phlegmatic & & & $\begin{array}{l}\text { Phleg- } \\
\text { matic } \\
\text { become } \\
\text { Interested }\end{array}$ & & & \\
\hline Melancholic & & & & $\begin{array}{l}\text { Melan- } \\
\text { cholic } \\
\text { passion }\end{array}$ & & $\begin{array}{l}\text { Melancholic } \\
\text { profes- } \\
\text { sionalism }\end{array}$ \\
\hline
\end{tabular}

\section{Sustainability}

To create ROBO-intelligences it is necessary to implement next steps.

The $1^{\text {st }}$ step. To create ROBOintelligences which possess 1st level elements - intelligences, emotions and temperaments it is necessary first of all to introduce them in robotic heart and robotic head.

This consists in creation corresponding Computer Based Information Systems for each of: Intelligences (7i), Tops (6s), Emotions (6), Temperaments (4), and Sentiments (positive \& negative)

The $2{ }^{\text {nd }}$ step. Next step in creation process of ROBO-intelligences consists in elaboration of their $2^{\text {nd }}$ level elements based on its 1 st level elements using Adaptable Tools for its definitions.

The $3^{\text {rd }}$ step. Each definition of ROBOintelligences 2 nd level elements is composed from definition of such it's characteristics as: pragmatics, syntax, semantics, environment, and examples. These definitions represent the Adaptable Algorithmic Knowledge Robotic Base which help to create real ROBOintelligence using Adaptable Tools for its development, verification, and experimenttation.

The $4^{\text {th }}$ step. Measure of ROBO- intelligence energies for each creativity, emotions, temperaments, sentiments.

These measures represent the Energetic Knowledge Robotic Base which help to create real ROBO-intelligence using Adaptable Tools for its development, verification, and experimentation.

Consciousness Society Creation Theorem: Having the Enegetic Knowledge ROBO-intelligence Warehouse it is possible algorithmically to implement in ROBOintelligences the creative, emotion, temperament and sensual human characteristics!

ROBO-intelligences will possess features which characterize highly creative people (natural intelligence). Character's creativity and emotion intelligences which are to be implemented in Character ROBOintelligences and Emotional ROBOintelligences are analysed and developed.

\section{REFERENCES}

1. Todoroi D. Conscience Society Creation, 6th Edition, ARA Publisher, University of California Davis, USA, 2017, 236 pages, ISBN: 978-1-935924-21-0, (Proc. Of the $6^{\text {th }}$ international TELECONFERENCE of young researchers "Conscience Society Creation", 
April 21-22, 2017, Bacău-București-BostonChicago-Chișinău-Cluj Napoca-Florida-IașiLos Angeles), http: //www.AmericanRomanianAcademy.org. 2. Todoroi D. Creative Robotic Intelligences, Editions Universitaires Europeennes, Saarbrucken, New York, 2017, 123 pages, ISBN: 978-3-639-65426-4.

3. Todoroi D. Creativity in Conscience Society, LAMBERT Academic Publishing, Saarbrucken, Germany, 2012, 120 pages. ISBN: 978-3-8484-2335-4

4. Moldova Suverana, 25.01.2017, Nr. 8(2095), utro.ru

5. Todoroi D., Micuşa.D. Sisteme adaptabile, Editura Alma Mater, Bacău, România, 2014, 148 pagini. ISBN 978-606-527-347-4.

6. Todoroi D. Crearea societăţii conştiinței, Materialele primei Teleconferinţe Internaţionale a tinerilor cercetători "Crearea Societăţii Conştiinţei”, 7-8 aprilie 2012, Chişinău, 169 pages / coord.: Dumitru Todoroi: ASEM, ARA, UAIC, ASE. ISBN 978-9975-75-611-2.

7. Society Consciousness Computers, Volume 1, 2014, Alma Mater Publishing House, Bacău, /Honorary Editor Dumitru Todoroi, Editor in Chief Elena Nechita/, 176 pages. ISSN 2359-7321, ISSN-L2359-7321.
8. Todoroi D. Crearea societăţii conștiinței, MaterialeleTeleconferinţei Internaţionale a tinerilor cercetători "Crearea Societății Conştiinţei”, Ed. a 3-a, 11-12 aprilie 2014, Chişinău, 129 pagini / coord.: Dumitru Todoroi: ASEM (Chisinau, Republic of Moldova), ARA (CalTech, Los Angeles, USA), UAIC (Iashi, România), ISU (Chicago, USA), UB (Bacău, România), UC (Cluj, România), ASE (Bucharest, România) . ISBN 978-9975-75-612-6.

9 . Society Consciousness Computers, Volume 2, Bacău-Bucureşti-Chicago-Chişinău-Cluj Napoca-Iași-Los Angeles, 2015, Alma Mater Publishing House, Bacău, 81 pages, ISSN 2359-7321, ISSN-L 2359-7321.

10. Society Consciousness Computers, Volume 3, Bacău-București-Boston-ChicagoChişinău-Cluj Napoca-Iaşi-Los Angeles, May 2016, Alma Mater Publishing House, Bacău, 183 pages, ISSN 2359-7321, ISSN-L23597321

11. Todoroi D. "Adaptable ROBOintelligences". // Proc. of the 41th ARA Congress, Craiova, Romania, July 19-July 22, 2017, ARA Publisher, University of California Davis, USA, ISBN: 978-1-93592421-0 (To be published), http: //www.AmericanRomanianAcademy.org/ 